\title{
Evaluating the effect of processing conditions and organoclay content on the properties of styrene-butadiene rubber/organoclay nanocomposites by response surface methodology
}

\author{
I. Ghasemi*, M. Karrabi, M. Mohammadi, H. Azizi \\ Iran Polymer and Petrochemical Institute, P.O.Box:14965/115, Tehran, I.R. Iran
}

Received 14 September 2009; accepted in revised form 4 November 2009

\begin{abstract}
In this work, basic mathematical models and response surface graphs have been used to illustrate the relationship between mixing parameters in internal mixer and properties of the SBR (styrene butadiene rubber)/organoclay composites. Using a Box-Behnken statistical design experiment methodology, the effects of mixing temperature $\left(80-140^{\circ} \mathrm{C}\right)$, mixing time (4-12 min) and nano filler amount (3-9 phr) in SBR nanocomposites on the properties (tensile properties, scorch time and Mooney viscosity) were evaluated. It was found that the mixing parameters (time and temperature) have the predominant role in properties and morphology of nanocomposite. The $R^{2}$ values (the $R^{2}$ values indicate the degree of agreement between the experimental results with those predicted by model) of all responses were above 0.85 . Increasing temperature and mixing time facilitated a better organoclay dispersion which resulted in a better tensile property. With increase in nanoclay amount in composite the scorch time and Mooney viscosity decreased. The morphology of nanocomposite was studied by XRD (X-ray diffraction) and TEM (Transmission electron microscope). Intercalation and exfoliation of the nanoclay were observed for samples with higher temperature and longer mixing time. Due to thermal degradation of the rubber matrix at $140^{\circ} \mathrm{C}$, tensile properties of the nanocomposite were decreased.
\end{abstract}

Keywords: nanocomposites, SBR, response surface methodology, tensile properties, Mooney viscosity

\section{Introduction}

There is a large body literature which explains the enhancement of the properties by incorporation of nano filler into polymers. Depending on nano filler types (nanofibers: nanotubes and whiskers, nano particle: silicate layer, nano size isotropic: titanium dioxide) the obtained nanocomposites can offer [1-4]:

- better mechanical properties

- lower permeability against the gases

- higher heat deflection temperature

- higher flame retardancy.

To achieve all of aforesaid improvements, the presence of fully exfoliated or intercalated and well dis- persed of nano fillers in polymer matrix is necessary.

In the melt intercalation method for producing of nanocomposite, the most important parameters which lead to gain this morphology are surface modification of nano filler by surfactants and proper processing conditions.

Many attempts have been focused on the describtion of the effects of processing parameters (in single and twin screw extruders and batch mixers) on the variation of nanocomposite morphology. Demirkol and Kalyon [5] studied different methods (batch and continuous) to produce nanocomposite. Their results point to the difficulty of the genera- 
tion of nanocomposites using melt compounding when the interfacial properties between the polymer melt binder and the organoclay are not favorable.

The effect of shear field on the morphology of nanocomposite has been reported by Homminga et al. [6]. They found the shear forces can facilitate the break-up of large-sized agglomerates, whereas the extent of further exfoliation of the mineral layers is determined by the compatibility between the polymer matrix and the mineral layers rather than shear forces.

Residence time and mixing efficiency as affective parameters in nanocomposite morpholology have been considered by many research groups. Borse and Kamal [7] reported that the larger residence time and higher mixing efficiency lead to higher degree of exfoliation and better mechanical properties of polyamide nanocomposites while Zhu and Xanthos [8] reported the residence time is a dominant factor in producing satisfactory polypropylene nanocomposite in extruder and that coupling of long residence time and high shear rate might result in poor exfoliation of nano filler.

Many attempts have been focused on the field of rubber/organo clay nanocomposites. The status and future trends [9], mechanical properties [10-12], rheology and thermodynamic [13] and effect of vulcanization ingredients [14] were studied.

In spite of many researches in the field of the extrusion of thermoplastic nanocomposites, there are only a few publications about affective parameters in batch mixer for producing rubber nanocomposite.

Other researchers [15] studied the effect of mixing on the properties of NR, SBR, BR and EPDM nanocomposites. Their results showed the mixing process plays a predominant role in formation nanometer scale dispersion structure. The effect of mixer type and mixing temperature on the properties of EPDM nanocomposite has been studied by Gatos and his coworkers [16]. It was found that increasing temperature and high shear mixing improve the mechanical performance of the rubber nanocomposite.
Using response surface methodology to optimize of process variables on flexural properties of epoxy/ organoclay nanocomposites has been reported by Chow and Yap [17].

The purpose of the present work is to investigate the effect of mixing time and temperature in the internal mixer and nano filler amount on the properties of SBR nanocomposites. To analyze the results, response surface methodology were applied. The properties as response were scorch time, Mooney viscosity and the tensile properties (tensile strength, modulus, and elongation at break).

\section{Experimental}

\subsection{Materials and sample preparation}

Poliran SBR-1500 containing 23.5\% of styrene was from Bandar Imam Petrochemical Co, Bandar Imam, Iran. The nanoclay was Cloisite 10A from Southern Clay, TX, USA with $1.92 \mathrm{~nm}$ initial gallery heights, modified with dimethyl benzyl hydrogenated tallow (2MBHT) quaternary ammonium, cation exchange capacity (CEC) was 110 mequiv/100 g. The activators (zinc oxide and Stearic Acid) and the curing agents (Sulfur and N-Cyclohexyl-2-benzothiazole sulfenamide (CBS)) purchased from local market. The formulation of nanocomposites was: SBR; $100 \mathrm{phr}$ (per hundred rubber), nanoclay (variable $1,3,5 \mathrm{phr}$ ), Stearic acid; $1.5 \mathrm{phr}$, Zinc oxide; $5 \mathrm{phr}$, CBS; $1.5 \mathrm{phr}$, sulfur; $1.5 \mathrm{phr}$.

The compounding was carried out using HAAKE internal mixer (SYS 90, USA) with a Banbury blade. At first, SBR was fed into the mixing chamber, the nanoclay and CBS were then added into the chamber after 2 minutes and mixing continued until predetermined time (in internal mixer). The processing conditions of nanocomposites preparation (time and temperature of mixing) and nano amount were given in Table 1. The other curing ingredients were mixed on two-roll mill (Schwabenthan, model Polymix 200L) for 4 min at ambient temperature.

Table 1. The Box-Behnken experimental design

\begin{tabular}{|l|r|r|r|r|r|r|r|r|r|r|r|r|r|r|r|}
\hline \multicolumn{1}{|c|}{ Sample No. } & $\mathbf{1}$ & $\mathbf{2}$ & $\mathbf{3}$ & $\mathbf{4}$ & $\mathbf{5}$ & $\mathbf{6}$ & $\mathbf{7}$ & $\mathbf{8}$ & $\mathbf{9}$ & $\mathbf{1 0}$ & $\mathbf{1 1}$ & $\mathbf{1 2}$ & $\mathbf{1 3}$ & $\mathbf{1 4}$ & $\mathbf{1 5}$ \\
\hline Mix temp. $\left[{ }^{\circ} \mathrm{C}\right]$ & 80 & 140 & 80 & 140 & 80 & 140 & 80 & 140 & 110 & 110 & 110 & 110 & 110 & 110 & 110 \\
\hline Mix time $[\mathrm{min}]$ & 4 & 4 & 12 & 12 & 8 & 8 & 8 & 8 & 4 & 12 & 4 & 12 & 8 & 8 & 8 \\
\hline Nano level $[\mathrm{phr}]$ & 6 & 6 & 6 & 6 & 3 & 3 & 9 & 9 & 3 & 3 & 9 & 9 & 6 & 6 & 6 \\
\hline
\end{tabular}


Vulcanization of the samples was carried out in a compression molding machine WCH202, Toyoseiki, Japan at $160^{\circ} \mathrm{C}$ for 15 minutes.

\subsection{Measurements}

Mooney viscosity $\left(\mathrm{ML}(1+4)_{100}\right)$ was investigated by 4309, ZWICK, Germany according to ASTM D1646 and rheometry test was made according to ASTM D2084 by 4308, ZWICK, Germany. The scorch time is the time to reach to $10 \%$ of maximum torque in the rheometry curing curve.

Tensile properties were measured according to ASTM D412 using Instron model 6025, UK. The cross head speed was $500 \mathrm{~mm} / \mathrm{min}$.

Wide-angle X-ray diffraction (XRD) measurements were carried out at room temperature on a D5000, Siemens, Germany. X-ray diffractometer with $\mathrm{CuK}_{\alpha}=1.541 \mathrm{~nm}$ with a generator voltage of $40 \mathrm{kV}$ and a generator current of $100 \mathrm{~mA}$. The scanning rate was $2 \%$ min over a range of 20 .

The morphology structure of the nanocomposites was investigated by an EM 208, Philips, Netherland transmission electron microscope (TEM) with an acceleration voltage of $100 \mathrm{kV}$. The ultrathin slides were obtained by an Ultracut UCT, Leica Germany at $-55^{\circ} \mathrm{C}$.

\subsection{Experimental design}

The Box-Behnken design was chosen as an experimental design for finding the exact quantitative relationship between properties of nanocomposite as the responses and different mixing conditions and content of nanoclay in the formulations. This design is rotatable which means that all the points in design area are at equal distance from the center points [18].

The number of design points $(N)$ is calculated by Equation (1):

$N=2^{k}+2 k+m$

where $k$ and $m$ are the number of factors and the number of replicates of the center points respectively. The replicate of center points is due to checking the reproducibility of the samples. The multiple linear regression analysis was used and the data were fitted as linear or second order equations. The order of equations are specified based on the lack of fit test and maximizing simultaneously
Table 2. Three levels Box-Behnken design

\begin{tabular}{|l|c|c|c|}
\hline \multicolumn{1}{|c|}{ Variables } & Low & Medium & High \\
\hline Time $[\mathrm{min}]$ & 4 & 8 & 12 \\
\hline Temperature $\left[{ }^{\circ} \mathrm{C}\right]$ & 80 & 110 & 140 \\
\hline Nano level $[\mathrm{phr}]$ & 3 & 6 & 9 \\
\hline
\end{tabular}

three parameters viz. $R^{2}$ (the $R^{2}$ values indicate the degree of agreement between the experimental results with those predicted by model), adjusted $R^{2}$ and predicted $R^{2}$.

A computer analysis has been done using commercially available package (MINITAB V13.2) to compute the equation constants.

In this study, the three variables in SBR nanocomposite at three levels Box-Behnken design was used which are shown in Table 2. According to this method 15 runs were necessary with three replicate of the center point. The design of experiment is shown in Table 2. A random sequence of experiments was implemented to minimize the sample preparation error.

Using response surface methodology with minimum number of experiments, it is possible to obtain quantitative equations for the effect of processing condition on the properties of SBR/organoclay nanocomposites. Application of this method has been reported in rubber field by Kukrejaa et al. [19].

\section{Results and discussion}

In Table 3 some statistical information and the equation of the model for each response are represented. The $R^{2}$ values for all responses are obtained in the range of $0.85-0.97$. Although, $R^{2}$ closer to 1 means that the model is more valid but range achieved for $R^{2}$ in this study is an indication of a very good fitting of the experimental data by the response surface method in the models.

To interpret of the variation of the mechanical properties, it is useful to start by expressing the morphology of the nanocomposite. Figure 1 shows the XRD diffraction pattern of organoclay, SBR and samples No.4, 5 after curing. The diffraction peak of organoclay at $2 \theta=4.59^{\circ}$ corresponds to $1.952 \mathrm{~nm}$ inter gallery distance (001). For sample No.5, it is obvious that after preparation of nanocomposites, diffraction peak of organoclay has been shifted to the lower $2 \theta(2.4 \mathrm{~nm})$ value which means that the intercalation morphology is formed. 
Table 3. Statistical data and the equation for different responses

\begin{tabular}{|c|c|c|c|}
\hline Response & $\mathbf{R}^{2}$ & Adjusted $\mathbf{R}^{2}$ & Equation of the model \\
\hline Scorch time $[\mathrm{min}]$ & 0.967 & 0.924 & $\begin{array}{l}2.3108+0.3488(\text { MTemp })+0.0925(\text { MTime })-0.8762(\mathrm{NL})+ \\
0.4887(\text { MTemp })^{2}+0.4087(\mathrm{NL})^{2}+0.3900(\text { MTemp } \times \text { MTime })+ \\
0.2025(\text { MTemp } \times \text { NL })-0.1250(\text { MTime } \times N L)\end{array}$ \\
\hline $\begin{array}{l}\text { Mooney viscosity } \\
(\mathrm{ML}(1+4))\end{array}$ & 0.859 & 0.853 & $\begin{array}{l}42.795+0.952(\text { MTemp })+0.349(\text { MTime })+1.489(\mathrm{NL})- \\
2.515(\mathrm{NL})^{2}+3.150(\text { MTemp } \times \text { MTime })+2.108(\text { MTemp } \times \text { NL })\end{array}$ \\
\hline Tensile strength [MPa] & 0.828 & 0.917 & $\begin{array}{l}1.7893+0.0499(\text { MTemp })+0.2135(\text { MTime })+0.2704(\mathrm{NL})- \\
0.0014(\text { MTemp })^{2}+0.0638(\text { MTime })^{2}-0.1154(\mathrm{NL}) 2+ \\
0.2093(\text { MTemp } \times \text { MTime })+0.0710(\text { MTemp } \times \text { NL })+0.0692(\text { MTime } \times N L)\end{array}$ \\
\hline Elongation at break [\%] & 0.877 & 0.853 & $\begin{array}{l}311.95+25.46(\text { MTemp })+16.06(\text { MTime })+29.69(\mathrm{NL})+ \\
31.07(\text { MTemp })^{2}-41.13(\text { MTimexMTemp })\end{array}$ \\
\hline
\end{tabular}

mixing time: MTime, mixing temperature: MTemp, nanoclay level: NL

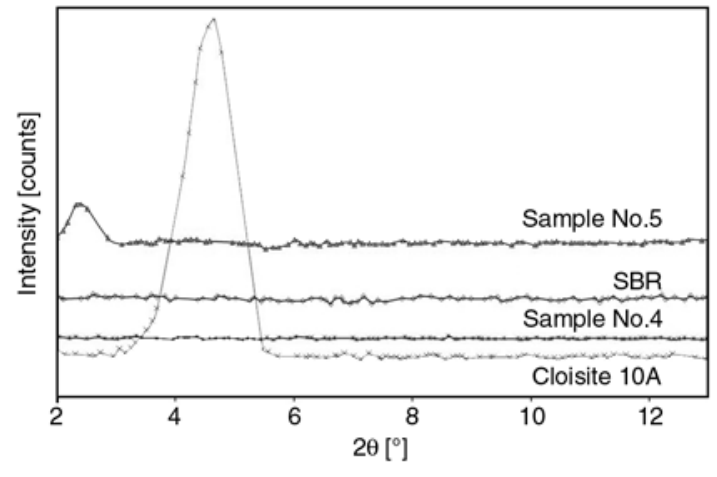

Figure 1. XRD diffraction patterns of organo clay, SBR and samples No.4 and No.5

The intensity of the X-ray patterns characterizing the degree of intercalation were changed with the mixing condition for samples with intercalation morphology. It seems that a good combination of time and temperature of mixing in sample No.4 $\left(12 \mathrm{~min}, 140^{\circ} \mathrm{C}\right)$ could achieve a fully exfoliated morphology so that the peak of organoclay disappeared in XRD pattern. As discussed later the mechanical properties are affected by these morphologies. Similar XRD patterns have been

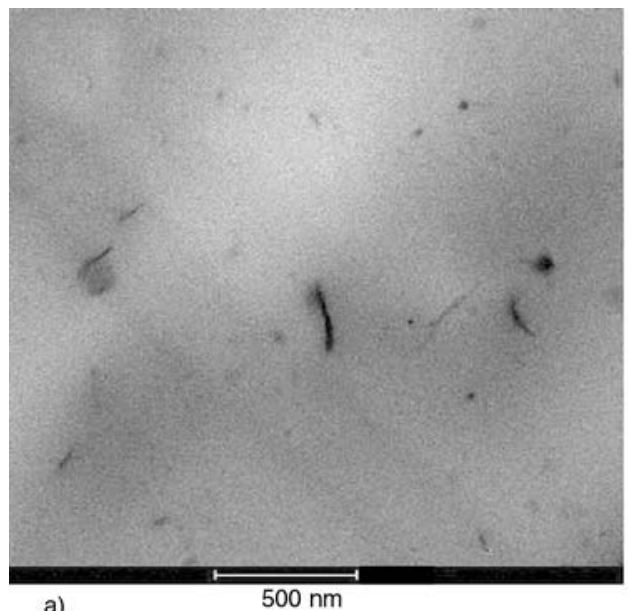

reported for exfoliated and intercalated SBR/organoclay composites in literatures [20-22].

By TEM, one can obtain information on the real state of spatial distribution of the nano particles. Figure 2 shows the typical TEM micrograph from intercalation morphology which presents the dispersion state of the rubber-clay nanocomposites (sample No.5). The micrographs are given in low and high magnification. The dark lines represent the intersection of the nano silicate layers while the white background corresponds to rubber matrix. As can be seen, there is some stacking nano silicate layers with the thickness of about 10-20 nm.

The effects of mixing time and temperature on the tensile strength of SBR/organoclay composite at three levels of nanoclay are shown in Figure 3. As shown with increase of mixing time, the tensile strength increases. It seems the mixing time has the main role in the variation of tensile strength. The highest increment in this property is attributed to a combination of high temperature and long mixing time for the all ranges of nanoclay. This is because the aforesaid condition facilitates the nanoclay

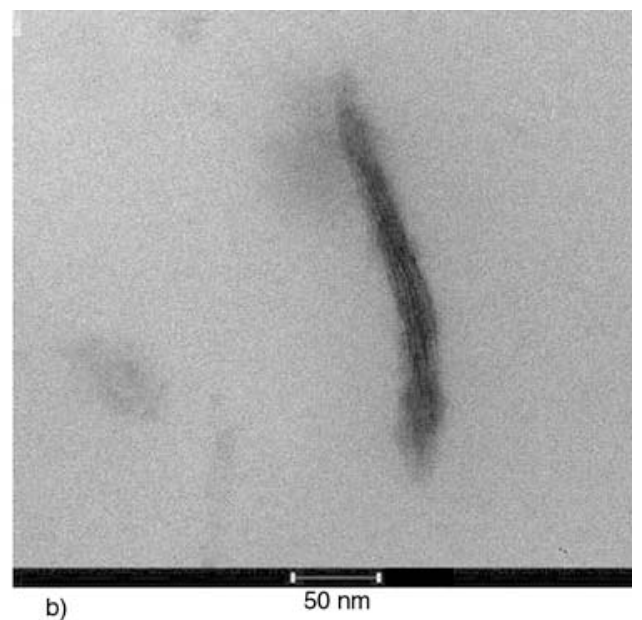

b)

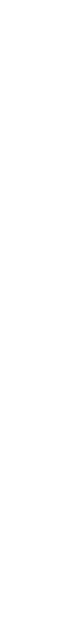



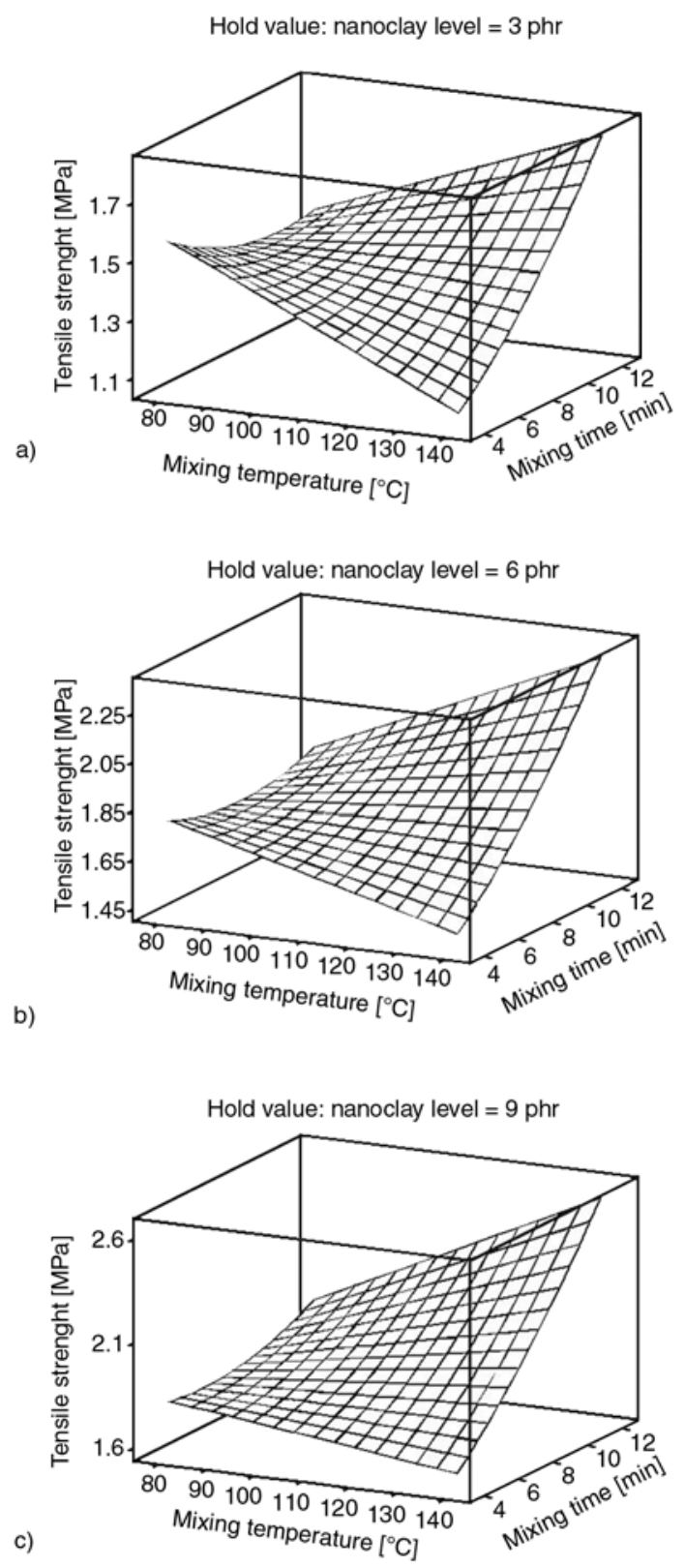

Figure 3. Tensile strenght versus mixing time and mixing temperature at different nanoclay contents:

a) $3 \mathrm{phr}, \mathrm{b}) 6 \mathrm{phr}, \mathrm{c}) 9 \mathrm{phr}$

intercalation process. Vaia and Giannelis [23, 24] interpreted the intercalation process by thermodynamic approach. They believe that the intercalation process is influenced by enthalpy of the system which is affected by the rate of diffusion of polymeric chain into the gallery of nanoclay. If the diffusion process of chains obey the Arrhenius equation $\left[D=D_{0} \exp (-\Delta E / R T)\right]$, the diffusivity of polymer into the nano layers will increase with temperature, where $D$ is the diffusion coefficient, $D_{0}$ is the pre-exponential factor of the diffusion process independent from the temperature, $\Delta E$ is the activation energy, $T$ is the absolute temperature and $R$ is the gas constant. In other words with the increase of temperature the mobility of rubber chains and consequently the rate of diffusion increases and so facilitates the intercalation process.

Another important point in Figure 3 is that at constant mixing time with increase of temperature, tensile strength decreases especially at $3 \mathrm{phr}$ of nanoclay concentration. It can be explained as follows: the tensile strength is balanced by two opposite effects, the positive effect is the interaction between rubber chains and nanoclay and the negative effect is the rubber degradation during mixing at high temperature. It should be considered that at longer mixing time (above 8 minutes), the positive effect of intercalation on the tensile strength is stronger than that of thermal degradation. This phenomenon can also be seen in sample containing $9 \mathrm{phr}$ of nanoclay where the slope of decreasing of tensile strength versus temperature (Figure $3 c$ ) is lower than those of other samples.

Elongation at break values versus time and temperature of mixing at three levels of nanoclays are demonstrated in Figure 4. As expected, the elongation at break is affected by temperature, mixing time and nanofiller content. It is well known that the elongation at break of rubber nanocomposite depends on the morphology of nanocomposites. Due to slippage of rubber chains in the presence of the free surfactant of nanoclay in exfoliated or intercalated morphology, the elongation at break increases [25-29]. In other words, the surfactant can act as a lubricant in the nanocomposites. In addition, the orientation of silica layers under tensile stress is another reason for increasing of elongation at break. The highest value for this property was related to sample No.8 which the conditions were $8 \mathrm{~min}, 140^{\circ} \mathrm{C}$ and $9 \mathrm{phr}$ of nanoclay. This trend indicates the longer mixing time at highest temperature led to the thermal degradation of SBR and consequently the elongation at break decreases. Mixing time and temperature dependency of scorch time is demonstrated in Figure 5 at three levels of nanoclay content. It is clear, with increase of nanoclay content in nanocomposite, the scorch time decreases. This can be attributed to presence of organic group of surfactant in nanaoclay. The formation of Zn-complex in the presence of sulfur and ammonium group of the surfactant has been reported for butadiene rubber with the sulfur/sulfonamide vulcanization systems by researchers 

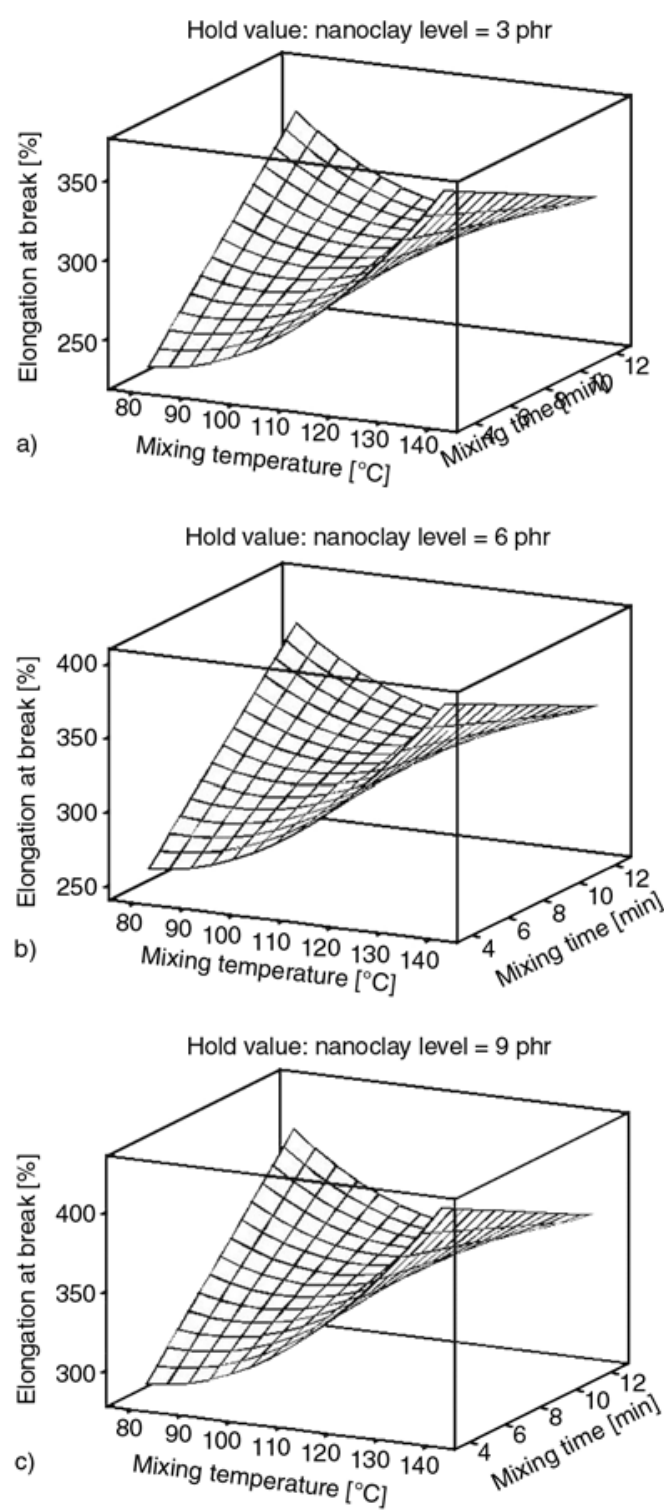

Figure 4. Elongation at break versus mixing time and mixing temperature at different nanoclay contents: a) $3 \mathrm{phr}$, b) $6 \mathrm{phr}$, c) $9 \mathrm{phr}$

[12]. They reported that the obtained chelate is more active than sulfenamid accelerators and it facilitates crosslinking reaction which leads to shorter scorch time. Similar results have been reported for scorch time of crosslinking of NR, SBR and ENR and it was found that the longer chain length of surfactant can also shorten the scorch time [11, 30-32]. As can be seen, the variation of scorch time versus temperature passes through a minimum of around $120^{\circ} \mathrm{C}$ for all samples. It seems, since at high temperature of mixing, the exfoliated morphology can be attained, ammonium groups are more available and so the possibil-
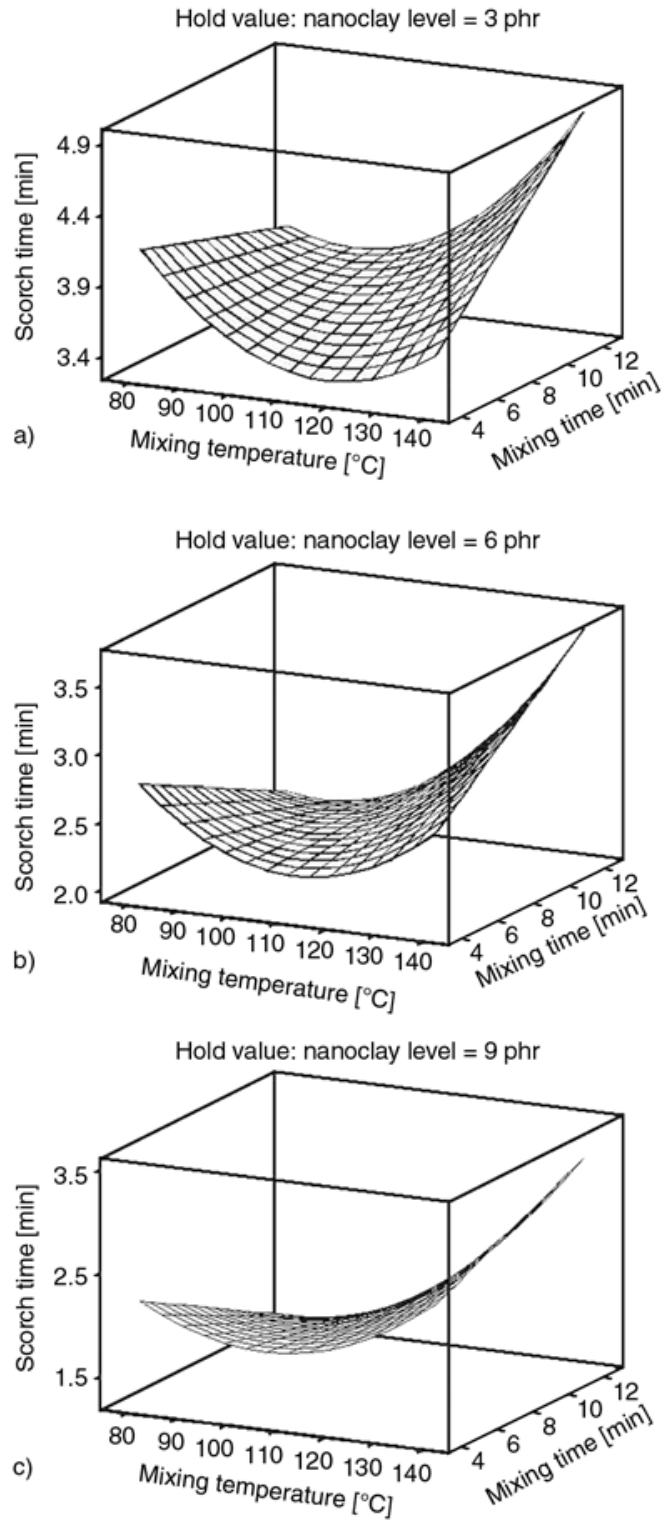

Figure 5. The variation of scorch time versus time and temperature of mixing at different nanoclay contents: a) $3 \mathrm{phr}$, b) $6 \mathrm{phr}$, c) $9 \mathrm{phr}$

ity of formation of Zn-complex is higher and crosslinking reaction leads to a shorter scorch time. After minimum point $\left(120^{\circ} \mathrm{C}\right)$ in this curve, the scorch time is affected by degradation of rubber chains especially at longer mixing time. In other words, during mixing, the chemical structure of rubber is changed by thermal degradation, and the rate of crosslinking reaction is somewhat affected by this phenomenon and the scorch time increases. The variation of Mooney viscosity versus mixing time and nano content at three levels of mixing temperature is shown in Figure 6. As can be seen at lower temperature (Figure 6a) Mooney viscosity 

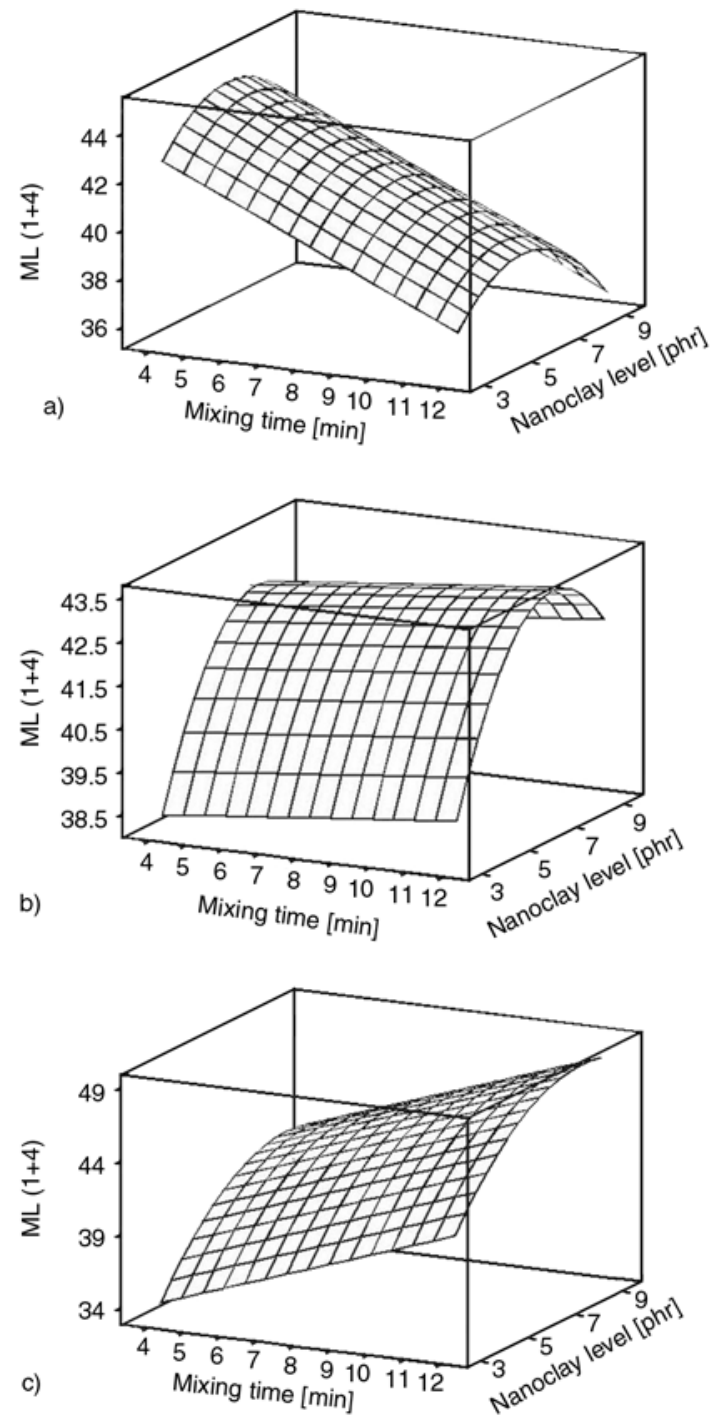

Figure 6. Mooney viscosity against mixing time and nano content at three levels of mixing temperatures: a) $80^{\circ} \mathrm{C}$, b) $110^{\circ} \mathrm{C}$, c) $140^{\circ} \mathrm{C}$

decreases with increasing mixing time. Generally, viscosity of rubber nanocomposites may be affected by lubricating effect of pendant chains of surfactant in intercalation or exfoliation morphologies. At lower temperature and longer mixing time the viscosity decreases. Under these conditions, the good dispersion of nano particles can be attained and the organic surfactant cause the slippage of rubber chains. This behavior may be also attributed to the orientation of silicate platelets upon shearing in Mooney viscosity test [33].

With increasing of temperature (Figure $6 b$ and $6 c$ ), the trend of Mooney viscosity variation changes and passes through minimum. The slope of incre- ment at $140^{\circ} \mathrm{C}$ is higher than at $110^{\circ} \mathrm{C}$. This is because the CBS accelerator can be activated at high temperature and partial crosslinking may occur in nanocomposites which was confirmed by extraction test before crosslinking. The undissolved part of this test implies partial crosslinking in the samples. The presence of rubber crosslink bonds in the compound is the main reason of increased viscosity which can overcome the effect of chain slippage and nanoclay orientations.

\section{Conclusions}

This study, aimed at investigating the effect of processing conditions (temperature and mixing time) and nano filler content on mechanical performance and structure of SBR/organoclay (MMT) composites using response surface methodology, the following conclusion can be drawn:

1. Mathematical models and response surface graphs are obtained to illustrate the relationship between mixing parameters in internal mixer and properties of the SBR/organoclay composites. It is obvious that this prediction suggests only a first approximation for other polymer grades and other equipments.

2. Increasing temperature and mixing time contribute to a better organoclay dispersion which results in improved mechanical properties.

3. Thermal degradation of the matrix occurred at high temperature $\left(140^{\circ} \mathrm{C}\right)$ of mixing and mechanical properties were affected by this phenomenon.

4. Intercalation and exfoliation of the clay were noticed for samples containing higher temperature and longer mixing time.

5. With increase of nanoclay content in composite the scorch time decreases.

Based on the present work by using the response surface methodology with minimum number of experiment, it is possible to obtain quantitative equation for properties of SBR/organoclay composite vs. different processing variables and nano filler content. With this equation one can optimize the nano filler content and the processing parameters for producing the nanocomposite with optimum properties. 


\section{References}

[1] Tjong S. C.: Structural and mechanical properties of polymer nanocomposites. Materials Science and Engineering Report, 73, 53-64 (2006).

DOI: $10.1016 /$ i.mser.2006.06.001

[2] Pegoretti A., Dorigato A., Penati A.: Tensile mechanical response of polyethylene-clay nanocomposites. Express Polymer Letters, 1, 123-132 (2007). DOI: 10.3144/expresspolymlett.2007.21

[3] Arroyo M., López-Manchado M. A., Valentín J. L. Carretero J.: Morphology/behaviour relationship of nanocomposites based on natural rubber/epoxidized natural rubber blends. Composites Science and Technology, 67, 1330-1347 (2007).

DOI: $10.1016 /$ j.compscitech.2006.09.019

[4] Hussain F., Hojjati M., Okamoto M., Gorga R. E.: Review article: Polymer-matrix nanocomposites, processing, manufacturing, and application: An overview. Journal of Composite Material, 17, 40-53 (2006). DOI: $10.1177 / 0021998306067321$

[5] Demirkol E. A., Kalyon D. M.: Batch and continuous processing of polymer layered organoclay nanocomposites. Journal of Applied Polymer Science, 104, 1391-1402 (2007).

DOI: $10.1002 / a p p .24362$

[6] Homminga D., Goderis B., Hoffman H., Reynaers H., Groeninckx G.: Influence of shear flow on the preparation of polymer layered silicate nanocomposites. Polymer, 46, 9941-9957 (2005).

DOI: $10.1016 /$ j.polymer.2005.07.059

[7] Borse K. N., Kamal M. R.: Melt processing effects on the structure and mechanical properties of PA-6/clay nanocomposites. Polymer Engineering and Science, 46, 1094-1108 (2006). DOI: $10.1002 /$ pen.20578

[8] Zhu L., Xanthos M.: Effects of process conditions and mixing protocols on structure of extruded polypropylene nanocomposites. Journal of Applied Polymer Science, 93, 1891-1899 (2004).

DOI: 10.1002/app.20658

[9] Karger-Kocsis J., Wu C-M.: Thermoset rubber/layered silicate nanocomposites. Status and future trends. Polymer Engineering and Science, 44, 1083-1093 (2004).

DOI: $10.1002 /$ pen.20101

[10] Sengupta R., Chakraborty S., Bandyopadhyay S., Dasgupta S., Mukhopadhyay R., Auddy K., Deuri A. S.: A short review on rubber/clay nanocomposites with emphasis on mechanical properties. Polymer Engineering and Science, 47, 1956-1974 (2005). DOI: $10.1002 /$ pen.20921

[11] Varghese S., Karger-Kocsis J., Gatos K. G.: Melt compounded epoxidized natural rubber/layered silicate nanocomposites: Structure-properties relationships. Polymer, 44, 3977-3983 (2003). DOI: $10.1016 / \mathrm{S} 0032-3861(03) 00358-6$
[12] Varghese S., Karger-Kocsis J.: Melt-compounded natural rubber nanocomposites with pristine and organophilic layered silicates of natural and synthetic origin. Journal of Applied Polymer Science, 91, 813-819 (2004).

DOI: 10.1002/app.13173

[13] Mousa A., Karger-Kocsis J.: Rheological and thermodynamical behavior of styrene/butadiene rubberorganoclay nanocomposite. Macromolecular Materials and Engineering, 286, 260-266 (2004).

DOI: $10.1002 / 1439-2054(20010401) 286: 4<260:: A I D-$ MAME260>3.0.CO;2-X

[14] Das A., Jurk R., Stöckelhuber K. W., Heinrich G.: Effect of vulcanization ingredients on the intercalation-exfoliation process of layered silicate in an acrylonitrile butadiene rubber matrix. Macromolecular Materials and Engineering, 293, 479-490 (2004).

DOI: $10.1002 / \mathrm{mame} .200700375$

[15] Wu Y-P., Ma Y., Wang Y-Q., Zhong L-Q.: Effects of characteristics of rubber, mixing and vulcanization on the structure and properties of rubber/clay nanocomposites by melt blending. Macromolecular Materials and Engineering, 28, 890-894 (2004).

DOI: $\underline{10.1002 / \mathrm{mame} .200400085}$

[16] Gatos K. G., Thomann R., Karger-Kocsis J.: Characteristics of ethylene propylene diene monomer rubber/organoclay nanocomposites resulting from different processing conditions and formulations. Polymer International, 53, 1191-1197 (2004).

DOI: $10.1002 /$ pi.1556

[17] Chow W. S., Yap Y. P.: Optimization of process variables on flexural properties of epoxy/organo-montmorillonite nanocomposite by response surface methodology. Express Polymer Letters, 2, 2-11 (2008).

DOI: $10.3144 /$ expresspolymlett.2008.2

[18] Montgomery D. C. M.: Design and analysis of experiments. Wiley, New York (2001).

[19] Kukrejaa T. R., Kumar D., Prasad K., Chauhan R. C., Choe S., Kundu P. P.: Optimisation of physical and mechanical properties of rubber compounds by response surface methodology - Two component modelling using vegetable oil and carbon black. European Polymer Journal, 38, 1417-1422 (2002). DOI: 10.1016/S0014-3057(02)00005-8

[20] Song M., Wong C. W., Jin J., Ansarifar A., Zhang Z. Y., Richardson M.: Preparation and characterization of poly (styrene-co-butadiene) and polybutadiene rubber/clay nanocomposites. Polymer International, 54, 560-568 (2005).

DOI: $10.1002 /$ pi.1732

[21] Jia Q-X., Wu Y-P., Wang Y-Q., Lu M., Zhang L-Q.: Enhanced interfacial interaction of rubber/clay nanocomposites a novel two-step method. Composites Science and Technology, 68, 1050-1056 (2008). DOI: 10.1016/j.compscitech.2007.07.006 
[22] Sadhu S., Bhowmick A. K.: Preparation and properties of styrene-butadiene rubber based nanocomposites: The influence of the structural and processing parameters. Journal of Applied Polymer Science, 92, 698-709 (2004).

DOI: 10.1002/app.13673

[23] Vaia R. A., Giannelis E. P.: Lattice model of polymer melt intercalation in organically-modified layered silicates. Macromolecules, 30, 7990-7999 (1997). DOI: $10.1021 / \mathrm{ma} 9514333$

[24] Vaia R. A., Giannelis E. P.: Polymer melt intercalation in organically-modified layered silicates: Model predictions and experiment. Macromolecules, 30, 80008009 (1997).

DOI: $\underline{10.1021 / \mathrm{ma9603488}}$

[25] Sadhu S., Bhomick A. K.: Morphology study of rubber based nanocomposites by transmission electron microscopy and atomic force microscopy. Journal of Materials Science, 40, 1633-1642 (2005). DOI: $\underline{10.1007 / \mathrm{s} 10853-005-0663-2}$

[26] Lee S-I., Hahn Y. B., Nahm K. S., Lee Y-S.: Synthesis of polyether-based polyurethane-silica nanocomposites with high elongation property. Polymers for Advanced Technologies, 16, 328-331 (2005). DOI: $10.1002 /$ pat.548

[27] Pramanik M., Srivastava S. K., Samantaray B. K., Bhowmick A. K.: Synthesis and characterization of organosoluble thermoplastic elastomer/clay nanocomposites. Journal of Polymer Science Part B: Polymer Physics, 40, 2065-2072 (2002).

DOI: $10.1002 /$ polb.10266
[28] López-Manchado M. A., Herrero B., Arroyo M.: Preparation and characterization of organoclay nanocomposites based on natural rubber. Polymer International, 52, 1070-1077 (2003).

DOI: $\underline{10.1002 / p i .1161}$

[29] Finnigan B., Martin D., Halley P., Truss R., Campbell K.: Morphology and properties of thermoplastic polyurethane composites incorporating hydrophobic layered silicates. Journal of Applied Polymer Science, 97, 300-309 (2005).

DOI: $10.1002 / a p p .21718$

[30] Wang S., Peng Z., Zhang Y., Zhang Y.: Structure and properties of BR nanocomposites reinforced with organoclay. Polymer and Polymer Composites, 13, 371-384 (2005).

[31] Arroyo M., López-Manchado M. A., Herrero B.: Organo-monmorillonite as substitute of carbon black in natural rubber compounds. Polymer, 44, 2447 2453 (2003).

DOI: $10.1016 /$ S0032-3861(03)00090-9

[32] Cataldo F.: Preparation and properties of nanostructured rubber composites with montmorillonite. Macromolecular Symposia, 247, 67-77 (2007).

DOI: $\underline{10.1002 / \text { masy.200750109 }}$

[33] Teh P. L., Mohd Ishak Z. A., Hashim A. S., KargerKocsis J., Ishiaku U. S.: On the potential of organoclay with respect to conventional fillers (carbon black, silica) for epoxidized natural rubber compatibilized natural rubber vulcanizates. Journal of Applied Polymer Science, 94, 2438-2445 (2004).

DOI: 10.1002/app.21188 